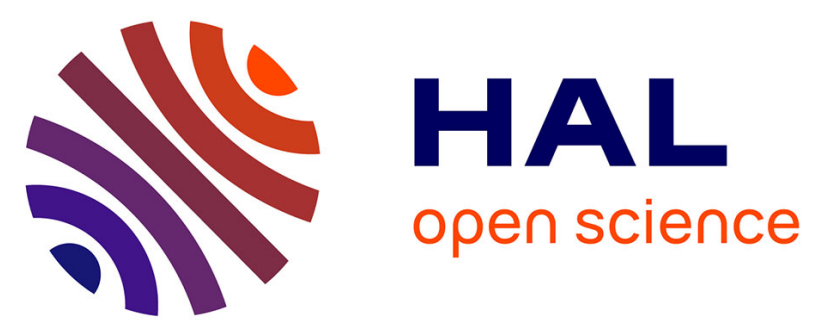

\title{
A systematic review of occupational radiation individual dose monitoring among healthcare workers exposed in Africa
}

\author{
Arnaud A. Gbetchedji, Gilles D. Houndetoungan, Hubert C. Hounsossou, \\ Neige M.Y. Journy, Nadia Haddy, Carolé Rubino, Olivier Biaou, Daton \\ Medenou, Kuassi M. Amoussou-Guenou, Florent de Vathaire, et al.
}

\section{To cite this version:}

Arnaud A. Gbetchedji, Gilles D. Houndetoungan, Hubert C. Hounsossou, Neige M.Y. Journy, Nadia Haddy, et al.. A systematic review of occupational radiation individual dose monitoring among healthcare workers exposed in Africa. Journal of Radiological Protection, 2020, 40 (4), pp.R141-R150. 10.1088/1361-6498/aba402 . hal-03109168

\section{HAL Id: hal-03109168 https://hal.science/hal-03109168}

Submitted on 10 Feb 2021

HAL is a multi-disciplinary open access archive for the deposit and dissemination of scientific research documents, whether they are published or not. The documents may come from teaching and research institutions in France or abroad, or from public or private research centers.
L'archive ouverte pluridisciplinaire HAL, est destinée au dépôt et à la diffusion de documents scientifiques de niveau recherche, publiés ou non, émanant des établissements d'enseignement et de recherche français ou étrangers, des laboratoires publics ou privés. 
A systematic review of occupational radiation individual dose monitoring among healthcare workers exposed in Africa

Arnaud A. Gbetchedji $\mathbf{M S}^{1,2,3,4}$, Gilles D. Houndetoungan $\mathrm{MD}^{4}$, Hubert C. Hounsossou PhD ${ }^{5}$, Neige Journy PhD ${ }^{1,2,3}$, Nadia Haddy PhD ${ }^{1,2,3}$, Carole Rubino MD, PhD ${ }^{1,2,3}$, Olivier Biaou MD, Daton Medenou PhD ${ }^{5}$, Kuassi M. AmoussouGuenou MD, PhD', Florent de Vathaire PhD ${ }^{1,2,3}$, Rodrigue S. Allodji PhD ${ }^{1,2,3,5, \ddagger}$

'Université Paris-Saclay, UVSQ, Univ. Paris-Sud, Inserm, Équipe Cancer and Radiation, CESP, 94807*, Villejuif*, France

${ }^{2}$ INSERM, CESP, Cancer and Radiation Team, Villejuif, 94805, France

${ }^{3}$ Gustave Roussy, Department of Clinical Research, Cancer and Radiation Team, Villejuif, 94805, France

${ }^{4}$ Faculté des Sciences de la Santé, Université d'Abomey-Calavi, P.O. Box 188, Cotonou, Bénin

${ }^{5}$ Ecole Polytechnique d'Abomey-Calavi (EPAC), Université d'Abomey-Calavi, 01 P.O. Box 2009, Cotonou, Benin

¥Corresponding author:

Rodrigue S. Allodji, Radiation Epidemiology Group / CESP - Unit 1018 INSERM, Gustave Roussy, B2M, 114, rue Édouard Vaillant 94805 Villejuif Cedex, Tel +33 (0) 1 42115498 / Fax +33 (0) 142115618

E-mail: rodrigue.allodji@gustaveroussy.fr 
Word Count: 3547 of 4000; Abstract: 291 of 300

Short running title: Review of radiation dose monitoring among radiology healthcare workers in Africa

KEYWORDS: dose monitoring, occupational exposure, diagnostic radiology, Africa, healthcare workers, radiography, diagnostic X-Ray, medical imaging, review. 


\begin{tabular}{|l|l|}
\hline Abbreviations & \\
\hline ALARA & As Low As Reasonably Achievable \\
\hline IAEA & International Atomic Energy Agency \\
\hline INIS & International Nuclear Information System \\
\hline OEW & Occupational Exposed Workers \\
\hline PRISMA & $\begin{array}{l}\text { Preferred Reporting Items for Systematic Reviews and Meta- } \\
\text { Analyses }\end{array}$ \\
\hline TLD & Thermo luminescent Dosimeter \\
\hline UNSCEAR & $\begin{array}{l}\text { United Nations Scientific Committee on the Effects of Atomic } \\
\text { Radiation }\end{array}$ \\
\hline
\end{tabular}

Funding: This work has been supported by the International Agency Energy Atomic (IAEA). 


\section{ABSTRACT}

Dosimetric monitoring is useful to requested limit exposures to ionizing radiation in medical occupational settings, and reduce subsequent health risks. Scientific literatures, such as UNSCEAR report, 2017 and International Atomic Energy Agency Report, 2014, updated informations on this subject, whereas, such a few African works were found. That's the reasons why we undertake this study, which consists in summarizing existing informations on monitoring external radiation exposure doses for whole body, from medical workers on this continent.

Using standard terms and combine the different keywords research for radiation dose monitoring among radiology healthcare workers in Africa, from the titles, abstracts, and full texts, we found 3139 articles in PubMed/MEDLINE, Google Scholar and INIS databases. Two reviewers screened the retrieved publications based on predefined eligibility criteria to identify relevant studies, extract key information from each, and summarize data in table.

A total of twenty potentially relevant articles were identified. Among these twenty articles, fifteen reported the overall average annual effective dose. Studies included in this systematic review represent an inventory of the radiation protection of medical workers in various countries of Africa, with a focus on the monitoring of occupational radiation exposure. The size of studied populations ranged between 81 and 5152 Occupational Exposed Workers. The mean annual effective doses ranged from 0.44 to $8.20 \mathrm{mSv}$ in all specialities of Medical sectors, while diagnostic radiology ranged from 0.07 to $4.37 \mathrm{mSv}$. For the nuclear medicine and radiotherapy from medical groups, the mean annual effective dose varied between 0.56 and $6.30 \mathrm{mSv}$. Industrial and Research/Teaching sectors's data which are presented in Table $2 \mathrm{~b}$ for comparison, varied between 0.38 to $19.40 \mathrm{mSv}$. 
In conclusion, more studies implemented on dosimetric monitoring in Africa are needed to get a real picture of occupational exposure in this continent.

KEYWORDS: Dose monitoring, occupational exposures, diagnostic radiology, Africa, healthcare, workers radiography, diagnostic X-Ray, medical imaging. 


\section{INTRODUCTION}

Occupational exposure to ionizing radiation occurs in many professions, including medicine, research/teaching and industry workers [1]. Diagnostic investigations using radiation have become a critical feature of medical practice. As such, it raises concern about the potential risk that these advancements may pose for both patients and professionals [2].

The cancer and non-cancer diseases caused by effects of radiations exposure on humans, has major implications to public health and radiation standard setting [3]. Public interest in the long-term effects of radiation on humans has then increased and has been focused on carcinogenic effects from protracted exposure to low doses.

The role of individual monitoring in the nuclear industry is undisputed, with the need for good record keeping and regular review [4]. Individual monitoring in medical sector is also important for the Occupational Exposed Workers (OEW). The monitoring of medical workers chronically exposed to ionizing radiation is common practice in many countries but remains limited on the African continent. This is evidenced in the United Nations Scientific Committee on the Effects of Atomic Radiation (UNSCEAR) 2017 report [1]. It states that literature dealing with medical exposure in Africa, Asia and Latin America is limited [1]. Our study will focus on Africa, because, according to the literature [5], it always remains the continent with the lowest participation rate in international surveys on radiation protection. The updating of information on this subject through scientific literature, such as UNSCEAR report, 2017 and International Atomic Energy Agency, 2014b, led us to undertake this study. That consists in making to summarize existing information on monitoring of doses external radiation exposure for whole body of medical workers on this continent. This will also highlight the improvement in dosimetric monitoring between the different countries, after analysis of the annual effective mean doses between different practices. 


\section{Methods}

\section{Search strategy and study selection}

We searched the PubMed/MEDLINE, Google Scholar and INIS databases using a combination of the following keywords with Booleans operators 'OR' 'AND': dose monitoring, occupational exposure, diagnostic radiology OR radiography OR diagnostic X-Ray OR medical imaging Africa AND medical workers, in the titles, abstracts, AND full texts. The reference lists of eligible articles were also reviewed to identify studies that we might have missed by searching terms in the titles and abstracts. We included articles, published in English or French up to the 31st of August 2019, with an update on 20th of May 2020, which reported results regarding the dose monitoring of occupational radiation exposure from IR. We excluded studies that only provided descriptions of the system of radiation protection or did not report information on the dose monitoring of occupational radiation exposure from ionizing radiation for whole body. Similarly, studies focused, only on the radiation protection of patients or monitoring doses of the hand in interventional radiology, were excluded. In this review, inclusion criteria were (i) article fully available in English or French languages (ii) articles which provided mean annual effective doses related to different medical, industrial and research specialities or teacher. The results of the identification and selection process are displayed in a flow diagram (Fig. 1), as requested in the Preferred Reporting Items for Systematic Reviews and Meta-Analyses (PRISMA) statement [6]. 

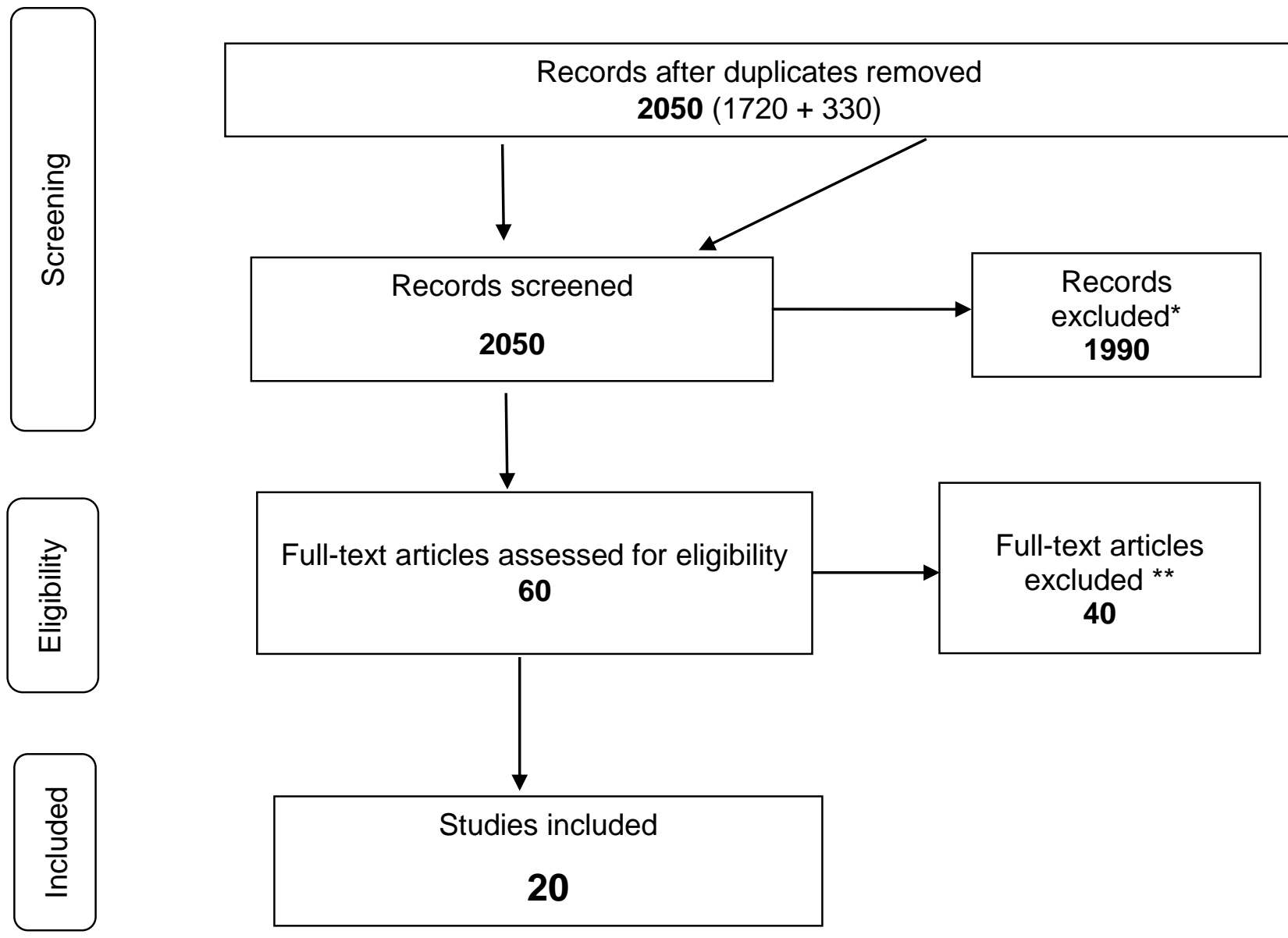

Fig. 1: PRISMA diagram selection process $s$ for paper published

On Pubmed: Monitoring of occupational exposures in diagnostic radiology radiation workers; on others sources: Monitoring, occupational exposures, diagnostic radiology; Dosimeter radiation workers medical imaging, medical X-Ray healthcare; Screening process: included the words "Africa". Criteria of eligibility: articles which report the individual dose's radiation about medical workers. Reasons for exclusion: * articles which report the dose's radiation about patients; **did not match inclusion criteria (i.e., radiation protection studies investigating the doses monitoring for whole body of medical workers). 


\section{Data extraction}

Information on country, study design, source population, sample size and period were extracted from the articles using a predefined data extraction form (Table 1). Data extraction was performed independently by two reviewers (AG, RA), who crosschecked their reports to validate the information extracted from the original articles and reach a consensus data synthesis.

\section{Results}

\section{Study Selection and Characteristics}

Using the defined key words, three thousand one hundred and thirty-nine (3139) articles were identified (Fig. 1). At the end, the twenty selected studies have been published between at 1986 to 2018 . These articles provides the dosimetric monitoring of workers exposed to ionizing radiation whole body and others described dosimetric monitoring practices. Among these twenty articles (Table 1) fifteen reported the overall mean annual effective dose (Tables $2 a$ and $2 b$ ). Five studies not reported in Table 2a and Table $2 \mathrm{~b}$ addressed issues of whether or not dosimetric monitoring exists in the facilities concerned or the assessment of compliance to international radiation protection standards; without reporting the individual radiation doses. From twenty studies, $70 \%$ and $15 \%$ studies were cross-sectional (reporting exposures during a oneyear period) and retrospective (reporting mean annual effective doses during a period of 16 years on average), respectively. The largest size of the source populations was 5152 provided in the field of diagnostic radiology by Ghana between 2000 and 2009 . It was followed by Tanzania with 757 diagnostic radiology workers on 1000, while Tapsoba et al. [7] reported only 81 medical workers on 157, in Ouagadougou at Burkina-Faso. The different studies reported data on workers exposed to ionizing radiation in all fields using the ionizing radiation, but more particularly in different 
specialities from medical sectors (Table 2a). All medical sectors, industrial and research/teaching's data are presented in Table $2 b$ for comparison. 
Table 1: Summary of twenty selected studies

\begin{tabular}{|c|c|c|c|c|c|c|}
\hline Authors & Country & Type of studies & Source population (sample size) & $\begin{array}{c}\text { Provided mean annual } \\
\text { individual doses } \\
\text { (Yes/No) }\end{array}$ & $\begin{array}{l}\text { Provided collective } \\
\text { annual doses } \\
\text { (Yes/No) }\end{array}$ & Period \\
\hline [8] & Burkina Faso & Longitudinal & OEW of Medical (3 to 121) & Yes & No & $2007-2010$ \\
\hline [7] & Burkina- Faso & Cross-sectional & $\begin{array}{l}\text { OEW in diagnostic radiology department } \\
\text { (81) }\end{array}$ & Yes & No & 2010-2011 \\
\hline [9] & Egypt & Retrospective & OEW (radioactive source) (27) & No & No & 2002-2012 \\
\hline [10] & Ethiopia & - & OEW (100 to 450$)$ & Yes & Yes & 1977-1988 \\
\hline$[11]$ & Ghana & Cross-sectional & $\begin{array}{c}\text { OEW of medicine, industrial, research and } \\
\text { education and teaching (650) }\end{array}$ & Yes & Yes & $2002-2007$ \\
\hline [12] & Ghana & Retrospective & $\begin{array}{l}\text { OEW of diagnostic radiology (5152), } \\
\text { radiotherapy (747), nuclear medicine (87) }\end{array}$ & Yes & Yes & $2000-2009$ \\
\hline [13] & Ghana & Cross-sectional & $\begin{array}{l}\text { OEW of medicine, industrial and } \\
\text { research/teaching: radiotherapy (8), } \\
\text { diagnostics (556), nuclear medicine (4) }\end{array}$ & Yes & Yes & 2008-2009 \\
\hline [14] & Ghana & Cross-sectional & $\begin{array}{l}\text { OEW in medicine, industrial, research and } \\
\text { education and teaching (254 to } 761 \text { ) }\end{array}$ & Yes & Yes & 1988-1995 \\
\hline$[15]$ & Kenya & Cross-sectional & $\begin{array}{c}\text { OEW in diagnostic radiology department } \\
(367)\end{array}$ & Yes & Yes & 2007 \\
\hline$[16]$ & Madagascar & Cross-sectional & $\begin{array}{l}\text { OEW in diagnostic radiology department } \\
(260)\end{array}$ & Yes & No & $1990-2000$ \\
\hline [17] & Malawi & Cross-sectional & $\begin{array}{l}\text { OEW in diagnostic radiology department } \\
\text { (Number of workers not defined) }\end{array}$ & No & No & 2018 \\
\hline [18] & Nigeria & Longitudinal & $\begin{array}{l}\text { OEW of medicine, industrial, and research } \\
(640)\end{array}$ & Yes & Yes & $1990-1999$ \\
\hline [19] & Nigeria & Cross-sectional & OEW of Medical (30 to 192) & Yes & Yes & 1999-2001 \\
\hline [20] & Nigeria & Cross-sectional & Radiographs (500) & No & No & 2009 \\
\hline [21] & Nigeria & Cross-sectional & OEW (Number of workers not defined) & No & No & 2011 \\
\hline [22] & Nigeria & Cross-sectional & OEW of medicine and industrial (500) & Yes & Yes & $2000-2001$ \\
\hline [23] & Nigeria & Cross-sectional & $\begin{array}{l}\text { OEW of medicine, radiographers and } \\
\text { radiologists (59) }\end{array}$ & Yes & No & $2005-2007$ \\
\hline$[24]$ & Sudan & Cross-sectional & $\begin{array}{c}\text { OEW in cardiology department (Number } \\
\text { of workers not defined) }\end{array}$ & No & No & 2010 \\
\hline [25] & Tanzania & Retrospective & $\begin{array}{c}\text { OEW in medicine, industrial, research and } \\
\text { education and teaching (730) }\end{array}$ & Yes & Yes & 1996-2010 \\
\hline [26] & Tanzania & Cross-sectional & $\begin{array}{l}\text { OEW in medicine, industrial, research and } \\
\text { education and teaching (1000) }\end{array}$ & Yes & Yes & $1986-1997$ \\
\hline
\end{tabular}




\section{Annual effective mean dose}

Among the included studies, fifteen had published the individual radiation doses. The Thermoluminescent Dosimeter (TLD) was the monitoring equipment in all studies. It is worn at chest height requested by IAEA [27]. It reported an overall mean annual effective dose in medical, industrial and research/teaching fields. Considering the different doses provided by the studies summarized in Table $2 \mathrm{~b}$, the mean annual effective doses ranged from 0.44 to $8.20 \mathrm{mSv}$ in all specialities of Medical sectors, while diagnostic radiology ranged from 0.07 to $4.37 \mathrm{mSv}$ (Table 2a). For the Nuclear medicine and radiotherapy specialities of medical sector, the mean annual effective dose varied between 0.56 and $6.30 \mathrm{mSv}$ (Table 2a).

Table 2a: Summary of height articles from the fifteen included studies reporting mean annual individual doses for different specialities of medical sectors

\begin{tabular}{|c|c|c|c|c|}
\hline \multirow[b]{2}{*}{ Authors } & \multirow{2}{*}{$\begin{array}{c}\text { Type of } \\
\text { dosimeter }\end{array}$} & \multicolumn{3}{|c|}{ Mean annual individual doses (in mSv) } \\
\hline & & $\begin{array}{l}\text { Diagnostic } \\
\text { Radiology }\end{array}$ & Nuclear Medicine & Radiotherapy \\
\hline [12] & TLD & 2.94 & 6.30 & 5.24 \\
\hline [25] & TLD & 1.50 & 1.50 & - \\
\hline [23] & TLD & 4.37 & - & - \\
\hline [14] & TLD & 0.80 & 0.56 & 1.12 \\
\hline [7] & TLD & $0.07-0.47$ & - & - \\
\hline [15] & TLD & 2.52 & - & - \\
\hline [8] & TLD & $\begin{array}{c}\text { In mean } 85.22 \% \text { of } \\
\text { doses }<0.10\end{array}$ & - & - \\
\hline [16] & TLD & $0.90-2.00$ & - & - \\
\hline
\end{tabular}

TLD $=$ Thermoluminescent Dosimeter.

Table 2b: Summary of seven articles from the fifteen included studies reporting mean annual individual doses for all specialities of medical sectors and others sectors (Industrial/ Research/Teaching)

\begin{tabular}{ccccc}
\hline & & \multicolumn{2}{c}{ Mean annual individual doses (in mSv) } \\
\cline { 3 - 5 } Authors & $\begin{array}{c}\text { Type of } \\
\text { dosimeter }\end{array}$ & Medical sectors & Others sectors \\
\cline { 3 - 5 } & & & Industrial & $\begin{array}{c}\text { Research/Teaching } \\
\text { group }\end{array}$ \\
\hline$[18]$ & TLD & 8.20 & - & 4.39 \\
\hline$[10]$ & TLD & 4.51 & 0.54 & - \\
\hline$[11]$ & TLD & 0.57 & 0.54 & - \\
\hline$[13]$ & TLD & 0.44 & $\mathbf{4 0 - 1 9 . 4 0}$ & - \\
\hline$[19]$ & TLD & $3.20-3.70$ & 0.92 \\
\hline$[26]$ & TLD & 1.68 & 16.25 & - \\
\hline$[22]$ & TLD & 2.7 & & 0.93 \\
\hline
\end{tabular}

TLD $=$ Thermoluminescent Dosimeter. 


\section{Discussion}

The updating of information on this subject through scientific literature, such as UNSCEAR report, 2017 and International Atomic Energy Agency, 2014b, where African countries were very little represented, led us to undertake this study which consists in making to summarize existing information on monitoring of doses external radiation exposure for whole body of by medical workers on this continent. Studies included in this systematic review represent, across various countries, an update of dosimetric's doses monitoring of medical workers in Africa, with a focus on the monitoring of occupational radiation exposure in diagnostic radiology sector. Because a wide numbers of medical workers are exposed to lower doses which may not be without consequences. We were able to find articles only from 11 countries out of 54 in Africa. This number is not representative as monitoring programs are available in some other countries, but they did not published papers on occupational radiation doses. The annual mean effective doses were provided by a little less than half of the studies selected for several exposed groups (medical, industry and research/teaching groups). The scarcity of dose monitoring data in African countries may be explained in part by the low participation rates of these countries in International Atomic Energy Agency (IAEA) technical studies. The results showed that, out of 55 countries that participated in the study from IAEA on individual dosimetry's monitoring of Interventional Cardiology from medical sector [5], only 2 were in Africa, and it had the lowest participation rate of $6 \%$ ( 2 countries among 32 representing the total number of participating countries). No specific study produced by the IAEA, for the field of diagnostic radiology and nuclear medicine was found.

In addition, several African countries (Benin, Burundi, Green cap, Central African republic, Comoros, Republic of Congo, Djibouti, Equatorial Guinea, Eritrea, Guinea, Guinea-Bissau, Lesotho, Liberia, Malawi, Rwanda, Chad, Togo) [28] do not yet have 
a dosimetry service functional in their country, despite the steps taken by the Mission Radiation Protection Advisory Team, IAEA, since 1984 [29]. However, the countries that have some may not publish the results of their surveillance. During the IAEA meeting in 2017 in Africa as part of Strengthening National Capabilities on Occupational Radiation Protection, 21 out of 28 participating countries had a dosimetric monitoring program [28]. The IAEA would have declared that only 17 countries participated in an intercomparison study [28]. This would confirm the thesis of the UNSCEAR 2017 report from the low participation of African countries in the studies.

The requested dose limit for effective dose is $20 \mathrm{mSv}$ per year on average over 5 consecutive years (100 mSv in 5 years) and $50 \mathrm{mSv}$ in one year [30]. A wide range of data has been produced by the different articles that have been selected. But as part of our study, we also compared the mean annual effective doses between medical practices on the one hand and between disciplines on the other hand. In medical sector's workers in study carried out by Farai and Obed, the OEW have received a mean annual effective dose above the $1 / 3$ of $20 \mathrm{mSv}$, annual dose limit requested. However, in three articles some extreme values are above the annual requested dose limit $[8,14,26]$. That is the case of one OEW from study carried out in Burkina Faso in 1990 by Yakoro et al. [8] where the value is $42.84 \mathrm{mSv}$ in two months monitoring. The reason advanced by authors is the improper location of the said dosimeter. That is the same reason provided by others authors.

In all height articles (Table 2a), the diagnostic radiology group had the lowest values and for seven articles in Table 2b, the medical sectors presents the lowest values of mean annual effective doses, except for the study by Farai and Obed [18]. We also found, when a comparison was made between the mean of the annual effective doses inside the medical specialities (diagnostic radiology, nuclear medicine and 
radiotherapy), diagnostic radiology was favoured, presenting the low annual effective dose means. However, we have observed in this study between different countries, the mean annual effective doses ranged from 0,07 to $4.37 \mathrm{mSv}$ (Table 2a), between 2011 and 2007, at Burkina Faso and Nigeria respectively, for the diagnostic radiology group. This difference observed from one country to another can be explained by the fact that organizational characteristics of medical fields can be different. Improvement of practices and devices over time can influence exposure time. That is the reason why the mean annual effective doses has decreased between period from 2007 to 2011 between Burkina Faso [7] and Nigeria [23]. However, we observe that in the years 2007, at the level of the diagnostic radiology sector, several countries presented the highest annual dose means values $[12,15,23]$. That is for the same reason that between 1990 to 1999 and 2008 to 2009 for studies carried out in Nigeria [18] and Ghana [13] respectively, there is a decreasing considerable of mean annual effective doses. The same trends are observed through the studies performed by Bayou et al. [10] at Ethiopia and Gordon et al. [11] at Ghana, where the mean annual effective doses decrease from 4.51 to $0.57 \mathrm{mSv}$ between 1988 and 2011, respectively. However, we note the heterogeneity of mean annual effective doses for the same year where the measures carried out between different countries, in medical sectors. The types of device (high or low dose rate) or radiation protection systems takes in place can explain this heterogeneity. The same conclusion on improvement of practices, can be drawn regarding to the comparative study intra-countries of the annual effective mean doses for the medical sector between Gordon and Adjei's studies where the doses decrease from 0.57 to $0.44 \mathrm{mSv}$ between 2002 and 2009 in Ghana. In Nigeria, Farai and Ogundare's studies show a decrease in the annual mean effective doses from 8.20 to $3.70 \mathrm{mSv}$ between 1990 and 2001. In contrast to these two countries, the studies carried out in Burkina Faso show an opposite trend, from 2007 to 2011, the 
dose increased of $<0.10$ to $0.47 \mathrm{mSv}$ according to studies by Yakoro and Tapsoba. This situation is certainly due to a growth in radiological procedures performed on the same devices in recent years.

\section{Conclusion}

This study showed that few countries in Africa publish the results of their dosimetric monitoring. It also shows that the doses recorded are sometimes relatively high, hence the need to encourage systematic dosimetric monitoring of all exposed workers for better monitoring of their state of health.

The paucity of international publications of dosimetric monitoring data in African countries does not reveal the manifold efforts made by them to optimize the protection of workers and the public. However, several countries have shown, through published studies, the improvement of radiation protection occupational.

\section{Acknowledgments}

This work was supported by the Division for Africa, Department of Technical Cooperation of International Atomic Energy Agency (IAEA). We especially thanks to

Catherine Luccioni and Olivier Laurent for their real involvements in the reading and revising the manuscript. We are also grateful to Imène Mansouri and Françoise Terrier for their unfailing support and advice.

\section{Conflicts of Interest}

The authors declare that there is no conflict of interest.

\section{ORCID iDs}

\section{Alfred Arnaud Gbetchedji https://orcid.org/0000-0002-9100-0166}

Rodrigue S. Allodji http://orcid.org/0000-0002-1895-8415 


\section{REFERENCES}

[1] UNSCEAR 2016 Report of the United Nations Scientific Committee on the Effects of Atomic Radiation (New York: United Nations)

[2] Dauda A M, Ozoh J O and Towobola O A 2019 Medical doctors' awareness of radiation exposure in diagnostic radiology investigations in a South African academic institution South Afr. J. Radiol. 23

[3] Wang J X, Zhang L A, Li B X, Zhao Y C, Wang Z Q, Zhang J Y and Aoyama T 2002 Cancer incidence and risk estimation among medical X-ray workers in China, 19501995: Health Phys. 82 455-66

[4] International Atomic Energy Agency 2014 The information system on occupational exposure in medicine, industry and research (ISEMIR): industrial radiography.

[5] International Atomic Energy Agency 2014 The Information System on Occupational Exposure in Medicine, Industry, and Research (ISEMIR): interventional cardiology.

[6] Moher D, Liberati A, Tetzlaff J and Altman D G 2009 Preferred Reporting Items for Systematic Reviews and Meta-Analyses: The PRISMA Statement Annals of Internal Medicine 1517

[7] Tapsoba T L, Ouattara F, Ouédraogo S, Sanon H, Yanaba D H and Gansonré V 2012 État du suivi dosimétrique des travailleurs dans les services de radiologie de la ville de Ouagadougou Médecine Nucl. 36 539-44

[8] Yakoro A, Ouédraogo N and Traoré S 2010 First assessment of individual monitoring of medical workers occupationally exposed to ionizing radiation in Burkina Faso 7

[9] Alramlawi S A, Alsaqr A S, Zayat D M A and Galal M 2015 Assessing the Occupational Radiation Doses for Medical Workers at Cairo University Hospital Based on Job Categories 4

[10] Bayou T 1991 Levels of doses to radiological workers in Ethiopia: 1977-1988 Ethiop Med J 29 119-26

[11] Gordon S W, Schandorf C and Yeboah J 2011 Optimization of radiation protection for the control of occupational exposure in Ghana Radiat. Prot. Dosimetry 147 386-93

[12] Hasford F, Owusu-Banahene J, Amoako J K, Otoo F, Darko E O, Emi-Reynolds G, Yeboah J, Arwui C C and Adu S 2012 Assessment of annual whole-body occupational radiation exposure in medical practice in Ghana (2000-09) Radiat. Prot. Dosimetry 149 $431-7$

[13] Adjei D, Darko E O, Schandorf C, Owusu-Manteaw P and Akrobortu E 2012 Personal dose analysis of TLD glow curve data from individual monitoring records Radiat. Prot. Dosimetry 152 273-8

[14] Osei E K 1997 Occupational Radiation Exposure in Ghana Radiat. Prot. Dosimetry 71 207-14 
[15] Korir G K, Wambani J S and Korir I K 2011 Estimation of annual occupational effective doses from external ionising radiation at medical institutions in Kenya South Afr. J. Radiol. 15116

[16] Andriambololona R, Ratovonjanahary J F, Randriantsizafy R D, Rakotoson E and Razafindrabe R L 2002 Thermoluminescence external personnel monitoring of workers in diagnostic radiology in Madagascar Hep-Mad '01 Proceedings of the First Madagascar International Conference on High-Energy Physics (Antananarivo, Madagascar: World scientific) pp 13-5

[17] Chinangwa G, Amoako J K and Fletcher J J 2018 Investigation of the status of occupational radiation protection in Malawian hospital Malawi Med. J. 3022

[18] Farai, P. I and Obed, I. R 2001 Occupational Radiation Protection Dosimetry in Nigeria Radiat. Prot. Dosimetry 95 53-8

[19] Ogundare F O and Balogun F A 2003 Whole-body doses of occupationally exposed female workers in Nigeria (1999-2001) J. Radiol. Prot. 23 201-8

[20] Okeji M, Anakwue A and Agwuna K 2010 Radiation exposure from diagnostic radiography: an assessment of $\mathrm{X}$-ray beam collimation practice in some Nigerian Hospitals Internet J. Med. Update - EJournal 5

[21] Eze K, Marchie T, Eze T, Nzotta C and Okegbunam B 2011 The state of occupational radiation protection and monitoring in public and private $\mathrm{X}$-ray facilities in Edo state, Nigeria Niger. J. Clin. Pract. 14308

[22] O. Ogundare F and A. Balogun F 2003 Analysis of occupational doses of workers on the dose registry of the Federal Radiation Protection Service in 2000 and 2001 Radiat. Prot. Dosimetry 103 57-62

[23] Nzotta C C and Chiaghanam N O 2010 Occupational Radiation Dose to X-ray workers in Radiological units in South Eastern Nigeria 3

[24] Ahmed N A, Nayl A I and Suliman I I 2012 Equipment performance and radiation protection status in X-ray fluoroscopy units in Sudan Radiat. Prot. Dosimetry 148 17480

[25] Muhogora W E, Byorushengo E, Lema U S, Mboya G, Ngatunga J B, Sawe S, Katsidzita N M, Mikidadi S, Chuma F, Marco A and Hamed M I 2013 Occupational radiation exposure in Tanzania (1996-2010): status and trends Radiat. Prot. Dosimetry $153403-10$

[26] Muhogora W E, Nyanda A M, Ngaile J E and Lema U S 1997 Occupational dose trends in Tanzania 7

[27] International Atomic Energy Agency and International Labour Office 2018 Occupational radiation protection: general safety guide

[28] IAEA 2016 The Role of Dosimetry in Protecting Workers Exposed to Ionizing Radiation (VIENNE: IAEA)

[29] International Atomic Energy Agency 1989 IAEA Bulletin 1989.pdf 
[30] International Atomic Energy Agency A 2016 Radiation protection and safety of radiation sources: Basic international safety standards (Vienne: AIEA) 